\title{
La palabra como instancia terapéutica de la acedia en Evagrio Póntico. La salmodia frente al logismós de la incuria
}

\antiago Hernán Vázquez

CONICET / Universidad Nacional de Cuyo, Argentina

ORCID oooo-0002-2388-7172

Recibido el 19 de marzo de 2020; aceptado el 30 de mayo de 2020.

\begin{abstract}
Resumen
Evagrio Póntico es uno de los primeros grandes sistematizadores de la espiritualidad cristiana y, por lo mismo, de gran importancia en diversos desarrollos antropológicos y de espiritualidad en el medioevo. El tópico de la acedia resulta un ejemplo de ello. El presente trabajo examina esta concepción evagriana de acedia de acuerdo a algunas claves hermenéuticas otorgadas por dos de los estudiosos más importantes del pensamiento del Póntico. Una vez clarificado el concepto de acedia, avanza en la dilucidación del recurso de la palabra como instancia terapéutica, principalmente de la palabra de la salmodia. La acedia es, consecutivamente, incuria o descuido,

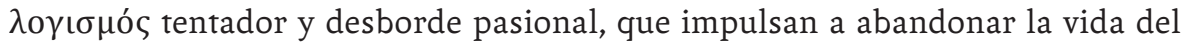
espíritu. Frente a ello, la palabra de la salmodia se erige en un importante recurso terapéutico para aquietar las pasiones, refutar los pensamientos y restaurar la esperanza.
\end{abstract}

PALABRAS CLAVE: EVAGRIO PÓNTICO; ACEDIA; LOGISMOI; SALMODIA; NEGLIGENCIA.

The Word as a Therapeutic Instance of Acedia in Evagrius Ponticus. Psalmody in front of the Logismós of the Incuria

\begin{abstract}
Evagrius Ponticus is one of the first great organizers of Christian spirituality and, therefore, of great importance in various anthropological and spirituality developments in the Middle Ages. The topic of acedia is an example of this. The present work examines this Evagrian conception of acedia according to some hermeneutical keys given by two important scholars of the Ponticus' thought. After clarifying the concept of acedia, the article advances in the elucidation of the resource of the word as a therapeutic instance, mainly of the word of Psalmody. The acedia is, consecutively, incuria or carelessness, tempting $\lambda$ oүı $\sigma \mu$ ó $\varsigma$ and passionate overflow, which impel to
\end{abstract}


abandon the life of the spirit. Against the acedia the word of Psalmody stands as an important therapeutic resource to quiet passions, refute thoughts and restore hope.

KEYWORDS: EVAGRIUS PONTICUS; ACEDIA; LOGISMOI; PSALMODY; NEGLIGENCE.

\section{Introducción}

En el marco de los estudios contemporáneos acerca de la obra de Evagrio Póntico (Konstantinvosky, 2016; Young, 2016; Kalvesmaki, 2016; Géhin, 2016; Ramelli, 2017; Peretó Rivas, 2017, 2018, 2019a, 2019b; Joest, 2018; Vázquez, 2019a, 2019b), pensador y monje cristiano de la Antigüedad Tardía, nos interesa observar y examinar el modo en que aparece el tópico de la capacidad terapéutica de la palabra en algunas de sus obras más significativas. Si bien este asunto se encuentra, con distintas modulaciones, en casi toda su obra, y nosotros ya lo hemos abordado en otros lugares (Vázquez, 2019a, 2017b), resulta de interés estudiarlo en el marco de la terapéutica de un padecimiento psicoespiritual identificado originalmente por Evagrio: la acedia. Es aquí, en efecto, donde aquella capacidad es actualizada de modo singular. En este sentido, un antecedente claro de este trabajo lo constituye el artículo de Rubén Peretó Rivas, que se ocupa precisamente de los recursos curativos de la acedia y otras "patologías" en el monacato medieval. La palabra emerge aquí como el recurso por antonomasia.

De este modo, el presente trabajo podría significar un aporte a la línea de estudio abierta por el autor argentino, en la medida en que intentaremos profundizar en la concepción evagriana de acedia de acuerdo a algunas claves hermenéuticas otorgadas por dos de los estudiosos más importantes del pensamiento evagriano. Una vez clarificado el concepto de acedia, avanzaremos en la dilucidación del recurso de la palabra como instancia terapéutica en el pensamiento evagriano, principalmente de la palabra de la salmodia.

Evagrio Póntico es, sin dudas, uno de los primeros grandes sistematizadores de la espiritualidad cristiana y, por lo mismo, resultó de gran importancia en diversos desarrollos antropológicos y de espiritualidad en el medioevo. En otro lugar, y ocupándonos de la noción de acedia en el pensamiento de Tomás de Aquino, hemos puesto en evidencia esta dependencia y gravitación doctrinal en muchos de los desarrollos del Póntico. ${ }^{1}$

La noción de acedia, acuñada originalmente por Evagrio, resulta, como lo ha observado Peretó Rivas, ${ }^{2}$ de una inusitada complejidad. Prueba de ello son las muchas definiciones y modificaciones semánticas que dicho término ha sufrido a lo largo

\footnotetext{
1 "En efecto, aunque el Aquinense no conoció de modo directo la obra de Evagrio, tanto por la histórica proscripción de la misma (sospechada de heterodoxia) cuanto por su desconocimiento de la lengua griega, la doctrina del monje del Ponto le llega por dos fuentes fidedignas que conoce a la perfección y que aparecen con gran frecuencia en su obra: Casiano y Juan Damasceno. En cuanto al primero se sabe que fue contemporáneo y discípulo de Evagrio y es este último una de sus principales fuentes" (Pichery, 2008: 65-67). Adriana Mallol señala, en este sentido, que Evagrio fue "el gran maestro de Casiano" (2011: 87), y Salvatore Marsili, por su parte, llega a decir que "en Casiano releemos a Evagrio" (1936: 161). Pues bien, Casiano, cuyas precisiones sobre la acedia son en muchos puntos una copia del texto evagriano, es el autor más citado por Tomás de Aquino a la hora de tratar el tópico de la acedia. En cuanto a san Juan Damasceno, también citado por el Aquinate al ocuparse de nuestro tema, y de quien se ha dicho que es la fuente por la que el filósofo de Aquino conoce a los Santos Padres e incluso a su maestro, la dependencia doctrinal con Evagrio es evidente en lo que se refiere a la acedia, pero no solo en ello: "El inicio del tratado De los ocho espíritus de la malicia de Juan Damasceno retoma los mismos términos de Evagrio, y el capítulo 6 del Tratado Práctico de Evagrio se encuentra reproducido casi literalmente en su tratado De la virtudy del vicio" (Nault, 2006: 73; cf. Vázquez, 2019a: 338).

2 "Acercarse al fenómeno de la acedia implica, inevitablemente, recurrir a Evagrio Póntico [...]. Sería difícil, sin embargo, aislar en [sus] escritos una definición de acedia, toda vez que el autor prefiere presentar aproximaciones diversas, generalmente a través de apotegmas o frases cortas, que van enriqueciendo gradualmente el concepto" (Peretó Rivas, 2017: $772-773)$.
} 
de la historia. ${ }^{3}$ Asimismo, y en el marco del redescubrimiento contemporáneo de la obra de Evagrio, los diversos estudios de la acedia en nuestro autor pocas veces ensayan -quizá porque ello no sea posible- una definición precisa del concepto, contentándose con aproximaciones segmentarias a algunos de los muchos aspectos o manifestaciones de este peculiar padecimiento. ${ }^{4}$

Existen, no obstante, entre los estudios de las últimas décadas, algunos dignos de mención que logran, a nuestro entender, unificar en una conceptualización coherente las muchas y contradictorias manifestaciones que la acedia tiene. Destaquemos entre estos los de Gabriel Bunge (2007) y Bernard Forthomme (2000, 2003, 2005). Este último autor, en particular, ha hecho un aporte único a los crecientes estudios contemporáneos acerca del pensamiento de Evagrio Póntico en general, y de la noción evagriana de acedia en particular. Su esfuerzo por arrancar de la polisemia la noción de acedia, identificando y delimitando lo que original y originariamente dicha noción designó, nos proporciona una vía de acceso para comprender por qué Evagrio propone la palabra como el recurso curativo por antonomasia de los padecimientos psicoespirituales por él mismo conceptualizados, y entre los cuales la acedia ocupa un lugar preponderante. Asimismo, los aportes de Gabriel Bunge nos otorgan valiosas claves hermenéuticas para inteligir el complejo fenómeno de la acedia.

\section{La acedia como negligencia y como logismós}

Bernard Forthomme llama la atención acerca del hecho de que Evagrio Póntico utilice para referirse a una experiencia aparentemente reconducible a la melancolía concepto presente en el pensamiento clásico que nuestro pensador, amplio conocedor

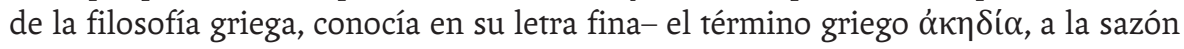
poco usado y poco determinado (Forthomme, 2005: 28; Despland, 2013: 78). Rastreando los primeros usos de dicho término y su significación general (Forthomme, 2005: 15-21; Peretó Rivas, 2018: 94-99; Guillaumont, 1971: 85-87), y confrontando estos con la conceptualización que de él realiza Evagrio Póntico, se puede entrever la razón de su elección: aquella experiencia de atonía, de dispersión, y de disgusto y cólera generalizados e inespecíficos que aqueja a los monjes, es reconducible en sus causas a aquella actitud espiritual de descuido o huida de sí que, en sentido general, designaba

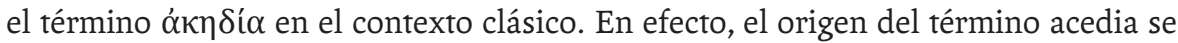

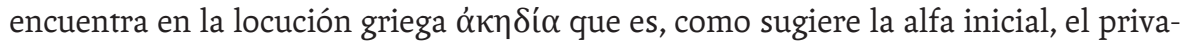

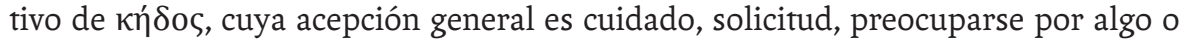
alguien. Su significado primario es, por lo tanto, "falta de cuidado" o "incuria". No obstante, el término es usado también, entre los griegos, con un sentido más preciso y de mayor implicancia filosófica. Él designa una falta especial de cuidado, una despreocupación o incuria singularísimas que los griegos creen menester especificar pues no se trata de una despreocupación cualquiera. La incuria que designa este término

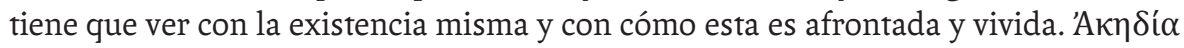
es, en fin, falta de interés o de cuidado por la sepultura, renuncia al duelo, ausencia de ritos funerarios, despreocupación ante la muerte. Tal despreocupación resulta para los griegos de una inusitada gravedad. Como indica Forthomme, los griegos adivinan en esta despreocupación, expresada en la incapacidad de guardar duelo, una hesitación dramática acerca de la propia identidad, una angustia manifiesta en cuanto al propio origen, naturaleza, ambiciones y destino (Forthomme, 2005: 16). La utilización, recogida por Forthomme, que hace Empédocles de nuestro término,

3 Las dos obras más completas para rastrear dicho itinerario son las de Forthomme (2000) y la de Wenzel (1966).

4 El reciente libro de Rubén Peretó Rivas Evagrio Póntico y la acedia propone -intentando salvar esta dificultad- aproximaciones sucesivas al concepto, que contemplan los diversos contextos en los que Evagrio habla del tema y las precisiones diversas que sobre él da a lo largo de toda su obra. 
expresa claramente esta idea. Dicho término designa para el presocrático un espíritu despreocupado de sí mismo. Se trata, en suma, de una despreocupación -la que se refiere a los difuntos- que manifiesta una incuria del hombre respecto de sí mismo, incuria por la cual, podríamos decir, se oblitera la dimensión especular de la muerte.

Forthomme encuentra en este alejamiento de sí mismo, en esta especie de sordera frente a la voz profunda del sí mismo, en suma, en este descuido y alienación de sí, la univocidad del concepto desde su emergencia pre-evagriana y su conceptualización original evagriana hasta su resurgencia contemporánea.

Ahora bien, por otro lado Forthomme insistirá repetidamente en la condición lógicolingüística de la acedia evagriana y cifrará allí la originalidad y la importancia de la conceptualización de nuestro pensador tardoantiguo. En efecto, la acedia es primariamente en Evagrio un $\lambda$ oүı $\sigma \mu$ ós, un pensamiento, "juicio tematizado o sugestión racional interior" (Forthomme, 2005: 21), que puede originarse por distintas razones: puede tratarse de una sugestión diabólica pues, como señala en Kephalaia gnostica, los demonios han aprendido el lenguaje de los hombres (KG IV.35) y le soplan, dicen y sugieren (Antirrh. I.2, 3, 17; II.4, 5; III.16, 37; V.26; VI.41, 43). Puede tratarse de un lenguaje interior que surge a partir de, primero, una particular situación espaciotemporal (el mediodía en la soledad abrumadora y en el calor pesado del desierto) ${ }^{5} \mathrm{y}$, segundo y unido a esto (pues la fuerza de las sugestiones se vincula a lo que sigue), de

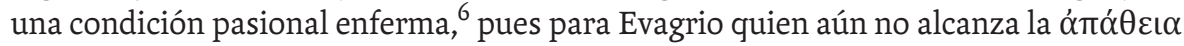
padece un desorden pasional cuasi patológico, la filautía, que espontáneamente lo inclina a preferir los placeres mundanos en lugar del conocimiento de Dios. ${ }^{7}$

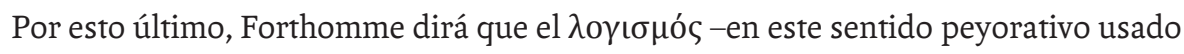
por Evagrio- es parte de la estructura del psiquismo en la medida en que este es afectado por el alejamiento ontológico de la unidad (Forthomme, 2000: 501). La acedia, como promotora de un alejamiento cada vez mayor, es como la condensación de toda la fuerza contraria a la unidad. Por ello Bunge, y aquí su aporte resulta de relevancia, dirá que la acedia entra al mundo al mismo tiempo que el hombre (2007: 57) y que, por lo tanto, resulta una experiencia intrínsecamente ligada a la existencia humana (2007: 92). El descuido que designa el término acedia, y que es siempre descuido del voũs, se enraíza en la filautía (condición del ser caído de Dios) y es su efecto inmediato. Los $\lambda$ oүı $\sigma \mu o i ́$ de la acedia tienen como raíz común esta condición, pues incluso aquellos a los que podría asignarse una causa preternatural no dejan de ser en Evagrio pensamientos apasionados, que encuentran en la filautía el terreno fértil para cultivarse. En este sentido se comprende que Bunge señale que "en tanto suma de todas las pasiones, [la acedia] es probablemente la expresión más pura y la más espiritual de la filautía de Adán, que se ha desviado de Dios para volverse a sí mismo" (2007: 70).

Forthomme dirá una y otra vez en su extensa obra dedicada a la acedia, que esta posee una estructura lógico-lingüística que explica su manifestación pasional compleja. "La acedia se revela como un cálculo y un lenguaje racional que implica una potencia de daño", dirá el autor francés (2000: 499). Y esto es -en recíproca causalidad- lo que genera el movimiento pasional patógeno o inductor de pecado. La acedia, en efecto, tiene expresiones contradictorias porque implica el desborde tanto de las pasiones concupiscibles cuanto de las irascibles. La clave que nos proporciona Forthomme nos

5 Como señala Evagrio, el demonio de la acedia ataca entre la hora cuarta y la hora octava (Prak. 12).

6 "Sin duda, no es el desierto, ni incluso los demonios que producen los $\lambda$ oүı $\sigma \mu o$, sino la parte apasionada del alma" (Forthomme, 2000: 530).

7 El tópico de la filautía lo hemos desarrollado en otro lugar (Vázquez, 2019c: 68-79). También puede verse Vázquez, 2018: 334. 
puede servir para comprender que detrás de esa manifestación contradictoria hay una lógica no consciente y operante a través del lenguaje interior. Escrutar esa lógica nos permite visualizar la continuidad existente entre esta concepción lógico-lingüística de la acedia con aquella que la comprende como un alejamiento y descuido de sí mismo enraizado en la filautía.

En efecto, dos de las posibles definiciones de acedia que encontramos en Evagrio pueden ser analizadas intentando penetrar en la posible estructura lógica, en las posibles construcciones lingüísticas que la sostienen. Estructura que, por lo demás, se puede rastrear dispersa en diversos lugares de la obra evagriana.

La primera definición la encontramos en sus Escolios a los Salmos. Dice allí: “А

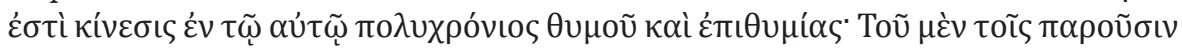

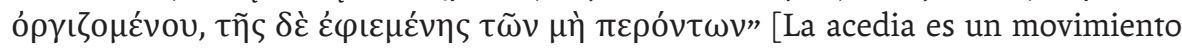
simultáneo, de larga duración, del irascible y del concupiscible; el primero, permanece furioso por aquello que está a su disposición; el segundo, por el contrario, se entristece por lo que ya no está] (Sch. PS. 118, 28). ${ }^{8}$

La segunda se encuentra en su obra Ocho espiritus de la maldad. Dice en este caso:

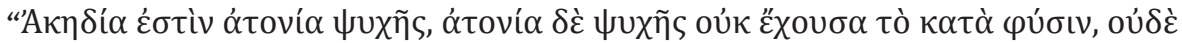

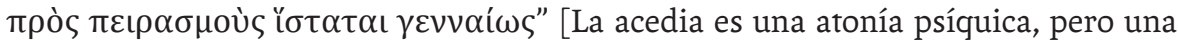
atonía que no es conforme a la naturaleza del alma, y no resiste naturalmente a las tentaciones] (De oct. spir. mal. 13).

Son diversos los elementos que entran en juego en estas definiciones. Abordémoslas intentando encontrar algún elemento que la vincule con nuestra aproximación inicial a la noción de acedia en tanto descuido o negligencia para consigo mismo.

Si hemos dicho con Forthomme que detrás de la acedia hay una estructura lógicolinguística, cabe preguntarse: ¿cuál es aquí el hilo lógico detrás de esta compleja manifestación pasional de la acedia? ¿Por qué hay ira contra lo presente y añoranza triste de lo ausente? ¿Por qué hay decaimiento de la tensión volitiva (atonía psíquica)?

Indagando en algunas de las sugestiones propuestas por el $\lambda$ oүı $\sigma \mu$ ó especificadas minuciosamente por Evagrio en su obra Antirrhético y en la descripción que hace del estado del monje acedioso, podemos comprobar que este $\lambda$ oүı $\sigma \mu$ ó sobre una condición afectivo-espiritual previa de descuido. Es este descuido la condición de su acción. Hay una condición afectiva propia de la situación espacio-temporal (el mediodía) y, como hemos visto con Bunge, de la condición humana misma (filautía) que propicia el descuido del voũc. Esta condición se cristaliza en pensamientos, en sugestiones racionales que dan razonabilidad al descuido de sí," intentando modificar la manera de autopercibirse. El descuido de sí puede consolidarse y sedimentarse en el alma por el asentimiento a los pensamientos. ${ }^{10}$

8 Las traducciones son propias salvo expresa indicación en contrario.

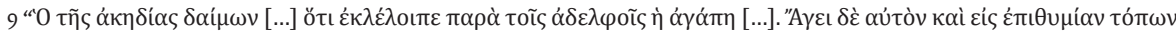

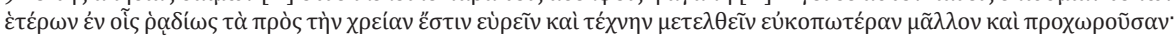

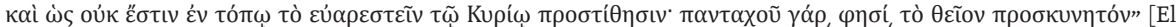
demonio de la acedia [...] le inspira la idea de que la caridad ha desaparecido de los hermanos [...], lo lleva a desear otros lugares, donde podrá encontrar fácilmente aquello de lo que tiene necesidad, y ejercer un oficio menos penoso que le reporte ventajas; añade que alabar al Señor no es un asunto de lugar, de hecho, en todas partes, se dice, la divinidad puede ser adorada] (Prak. 12). Como vemos, se procura justificar racionalmente aquí el abandono de la celda monástica, lo cual

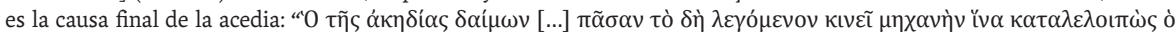

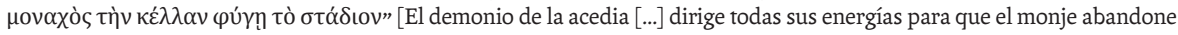
su celda y huya del estadio] (Prak. 12).

10 Algunos ejemplos de estas sugestiones, identificadas con precisión por Evagrio en su Antirrhético, son los siguientes: "Contra el pensamiento que por acedia va razonando: 'El demonio de la acedia es muy potente y yo no estoy en grado de sostener el asalto de sus pensamientos suscitados contra mí"” (Antirrh. VI.7). "Para el alma que quiere saber si verdadera- 
Pero esta breve exégesis del texto evagriano a partir de las claves hermenéuticas otorgadas por Forthomme y por Bunge, sirviéndonos para inteligir el complejo fenómeno de la acedia, nos permite a renglón seguido visualizar cómo y por qué Evagrio propone como recurso terapéutico la palabra. Decir que la acedia está estructurada como un lenguaje supone, dirá el autor francés, un fondo de inteligibilidad de la malignidad y una susceptibilidad de cura, de reencuentro de la tendencia maligna por la palabra de vida, la cual es apotegma, versículo antirrhético u oración (Forthomme, 2000: 499500). Asumir que esta estructura se funda en el descuido del voũs, en tanto tendencia inherente al ser caído que se ama a sí de modo desordenado (filautía), y que dicha estructura busca consolidar aquel descuido en una nueva autopercepción, implica sostener, por un lado, que la curación completa se da solo en el estado de ó $\operatorname{có}_{\theta} \theta \varepsilon \iota \alpha$, en la que el ser humano se cura de la filautía, y, por otro, que la palabra que puede curar es la que favorece la autorresignificación. Aunque no se pueda decir que la palabra en Evagrio es un paliativo terapéutico, sí debe entenderse que su acción está inscripta en el camino terapéutico más amplio de la búsqueda de la ór $\alpha \dot{\theta} \theta \varepsilon\llcorner\alpha$, y que favorece la consecución de esta. En este sentido, la palabra inscrita en este proceso, frente al padecimiento de la acedia, debe devolver -en virtud de su singular potencialidad especular- una imagen de sí reconstruida, debe promover el amor hacia la imagen real de sí: la del voũ que busca el retorno a la unidad.

Por esto, los diversos caminos que en Evagrio puede tomar la palabra para actualizar su capacidad terapéutica involucran siempre la puesta en juego de aquella virtualidad especular. La palabra del $a b b a$, de cuya necesidad para el monje en camino hacia la

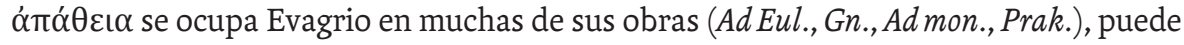
curar o contribuir a la curación porque ella busca que su receptor se comprenda a sí mismo desde su real naturaleza de voũc. Casiano, discípulo y contemporáneo de Evagrio, señala de modo explícito que las palabras del abba son como un espejo para el monje que las escucha (Conf.X.11.6). También en el método antirrhético, que es el camino más llano que toma la palabra para ejercer su acción curativa, se asume y actualiza esta fundamental virtualidad especular de la palabra que tiene la potencia de curar la acedia. En efecto, Evagrio encuentra el origen de este método en las réplicas de nuestro Señor Jesucristo contra Satanás, réplicas por las cuales, como señala Bunge, el Señor Jesús prueba su propia identidad (2007: 135). En el uso que el monje haga de este método habrá también una reafirmación de la propia identidad espiritual por la identificación con el texto de la Escritura.

Pero detengámonos brevemente en el tercer camino que para Evagrio puede tomar la palabra para ejercer una acción terapéutica. Se trata aquí de una palabra especial cuya acción connota un cúmulo de constelaciones psíquicas y espirituales dignas de atención: la palabra de la salmodia.

\section{La palabra de la salmodia}

$\mathrm{Al}$ referirse a la acedia en Los ocho espíritus de la maldad, y después de señalar que ella es, como vimos más arriba, "atonía del alma" contraria a la naturaleza, Evagrio dirá

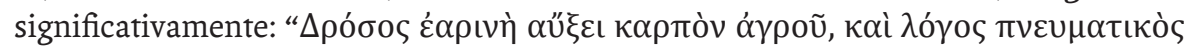

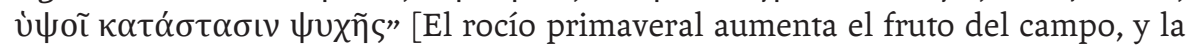
palabra espiritual eleva la condición del alma] (De oct. spir. mal. 13). El verbo que aquí traducimos como elevar es v̀ $\psi o ́ \omega$, que también puede ser traducido como levantar o

mente es arrojada a las tentaciones por los demonios cuando es abandonada por breve tiempo por los santos ángeles" (Antirrh. VI.17). "Contra el pensamiento de la acedia que nos proyecta una vejez larga, una pobreza amarga y sin consolación y enfermedades capaces de matar el cuerpo" (Antirrh. VI.32). 
exaltar. Pareciera que es la palabra espiritual la que levanta y eleva la condición del alma, la que puede sacarla de la atonía. ¿Cuál es esa palabra espiritual?

En otros lugares nos hemos ocupado de la importancia de la palabra del abba para la "curación" del alma (Vázquez, 2019a, 2017a). En lo que se refiere a la acedia, nuestro autor señala, en su Carta a Eulogio, que ella es el fruto final de la tentación de sustraerse a la palabra de aquel padre espiritual (Ad. Eul. 26).

Si la palabra del abba ha sido descartada, llevando a la acedia, hay otra "palabra espi-

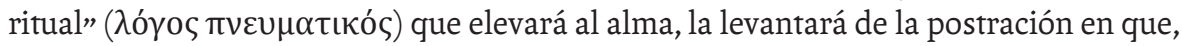
según nos dice Evagrio en aquella carta, ha caído, pues "los demonios han atrapado su cerebro" (Ad. Eul. 26). Esa palabra espiritual es explicitada en el Tratado Práctico:

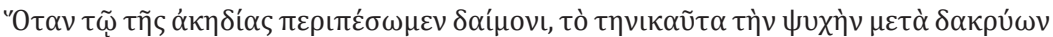

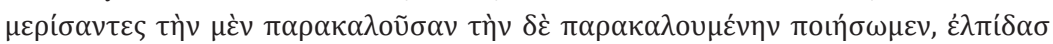

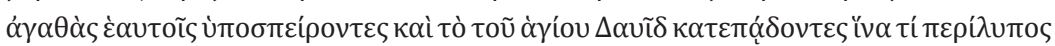

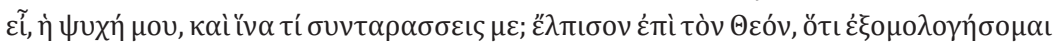

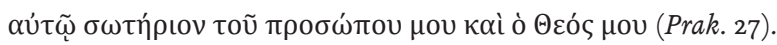

Cuando nos choquemos al demonio de la acedia, entonces, con lágrimas, dividamos nuestra alma en dos partes: una que consuela y la otra que es consolada, y, sembrando en nosotros buenas esperanzas, pronunciemos con el santo David este encantamiento: ¿Por qué estás triste, oh alma mía, y porqué te me trastornas? Espera en Dios, porque yo lo alabaré, Él la salud de mi rostro y mi Dios (Prak. 27).

Frente al ataque del demonio de la acedia, propone repetir con David un encantamien-

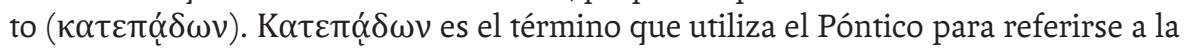
palabra del salmo 41, el cual libraría al alma de este demonio. "Palabra persuasiva" es la expresión elegida por la traducción italiana para dilucidar aquel término (Prak. 27; cf. Bunge, 2008). Si bien esta última traducción no es literal, resulta reveladora y coherente con la conceptualización evagriana. La carga semántica hodierna del término encantamiento, el cual sugiere casi inmediatamente la idea de hechizo mágico, hace optar a los traductores por una expresión que de mayor inteligibilidad a la propuesta evagriana. Y al hacerlo escogen precisamente la reveladora expresión de "palabra persuasiva". En efecto, es posible rastrear en Evagrio una doble significación

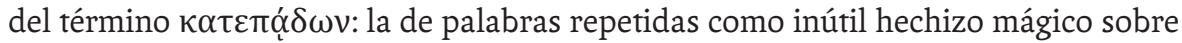
el alma (De mal. cogit. 19), y la de palabras que modifican efectivamente las disposiciones del alma, como en el capítulo del Tratado Práctico que venimos comentando. El encantamiento que libera y cura no lo hace por una virtud mágica sino, por el contrario, por su capacidad persuasiva. ${ }^{11}$ No es extraño, en este sentido, que el Libro de los Salmos sea, por lejos, el más usado en las réplicas a los pensamientos de la acedia en el Antirrhético, en tanto esta palabra da nombre a un método creado por Evagrio para combatir los $\lambda$ oүı $\sigma \mu o i ́$, que se funda en un dinamismo persuasivo natural.

Recordemos aquí que este método creado por Evagrio consiste en la selección de diversos textos de la Sagrada Escritura que sirven de confutación directa a las sugestiones

11 No podemos sino evocar aquí el o los sentidos en los que Platón usó el mismo término para hablar de las palabras que

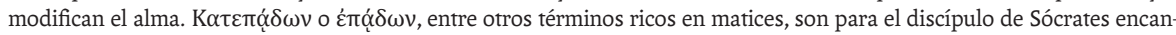
tamientos, conjuros o ensalmos que pueden ejercer un efecto benéfico sobre el alma en virtud de un dinamismo natural. "Esfuerzo racionalizador del ensalmo" le llamó Laín Entralgo a esta propuesta platónica (2005: 107 ss). Tampoco podemos dejar de recordar, en efecto, el ya clásico estudio de este médico español sobre el tópico de la curación por la palabra en la Antigüiedad Clásica, en cuyas últimas páginas se refiere a los maestros directos de Evagrio (Gregorio de Nisa, Basilio de Cesarea y Clemente Alejandrino) como aquellos que recogen la herencia clásica y dan un nuevo giro al tema (2005: 223). Asimismo resulta significativo que al referirse a Aristóteles, el médico español ensaye la posibilidad de un nuevo género persuasivo añadido a los cuatro del Estagirita: el terapéutico, el cual se fundaría, precisamente, en la virtualidad persuasiva de la palabra (2005: 174). Todo esto contribuye sin duda a iluminar la propuesta evagriana. 
concretas y variopintas de los ocho $\lambda$ oү $\sigma \mu$ ó. Se trata de textos significativos desde el punto de vista afectivo, cognitivo y espiritual, pues se han seleccionado cuidadosamente después de examinar largamente las conductas, las tendencias, las imaginaciones, los recuerdos y sugestiones verbales concretas que se producen en el marco de las ocho inclinaciones pecaminosas principales del alma caída. ${ }^{12}$ De este modo, y después de identificar claramente las distintas "modalidades psíquicas" en que puede presentarse un $\lambda$ oүı $\sigma \mu o$ í, se proponen palabras que son persuasivas -y así promotoras de curación- porque atienden a la naturaleza de dicha modalidad. Y, naturalmente en un contexto monástico, porque son "Palabra Sagrada" que, a imitación de Cristo, se oponen al Tentador que -como en otro lugar hemos demostrado (Vázquez, 2019c: 82 ss) - se vale de la dinámica psíquica del alma caída para proponer sus "palabras de perdición".

Dado que en la hora de la lucha no hallamos rápidamente en la Escritura las palabras idóneas para confutar a nuestros enemigos, los pérfidos demonios, pues éstas se encuentran desperdigadas y es difícil localizarlas, hemos compilado diligentemente las palabras de las Santas Escrituras para que nos armemos de ellas y procedamos con valor contra los 'filisteos' (Ex. 13: 17), de pie en la batalla como valientes y vigorosos soldados de Jesucristo, nuestro victorioso rey (Antirrh., Pról. 3).

En este contexto, la palabra de la salmodia parece contener, ante el padecimiento de la acedia, una virtualidad persuasivo-terapéutica particular pues es propuesta por Evagrio con insistencia al ocuparse de los remedios y de las réplicas contra dicho padecimiento.

En el caso del Antirrhético, nos encontramos frente a una cifra reveladora: de un total de cincuenta y siete réplicas al $\lambda$ oүı $\sigma \mu$ ó de la acedia, sacadas de veinticuatro libros distintos de la Sagrada Escritura (contando algunas cartas paulinas), dieciocho están sacadas del Libro de los Salmos, es decir, más del treinta por ciento. Después del Librode los Salmos, el más citado es el Deuteronomio con solo cuatro citas. El Libro de los Salmos parece ser el que mejor ejecuta la labor confutativa-terapéutica en el combate contra la acedia. En efecto, los dieciocho pasajes escogidos de dicho libro tienen una doble finalidad: atender a la pérdida de esperanza respecto a la posibilidad de llevar una vida conforme al voũs, con la tentación inherente de "huir del estadio", como escribe Evagrio en el Tratado Práctico. A esta pérdida de esperanza se oponen textos sálmicos que subrayan la relatividad de la experiencia afectiva y recuerdan al monje, o lo hacen consciente de, la naturaleza agónica del camino cristiano, hecho de momentos de combate, de cansancio y de abandono que no durarán para siempre. Por otro lado, la segunda finalidad, casi indiscernible de la anterior, es que las palabras de los salmos pongan en evidencia que el oscurecimiento del propio espíritu producido por la acedia resulta una experiencia inherente al itinerario espiritual (Antirrh. VI.10-27). Por ello, comentando el tema de los remedios de la acedia, Robert Daly dirá: "Los remedios para librarse de esta tentación son tratar de alentar (¿a uno mismo?) y ser alentados a sembrar semillas de una firme esperanza cantando salmos" (Daly, 2007: 33).

En este sentido, resulta evidente que Evagrio propone como remedio claro frente a la acedia la identificación con David, el autor inspirado de los Salmos. Se comprende así que en su tratado Sobre los pensamientos nuestro autor diga que Dios, que ha confiado a los hombres las representaciones de este siglo (mediante las cuales conoce y a partir de las cuales puede padecer el hostigamiento de los $\lambda$ oүı $\sigma \mu$ oí que son "representaciones apasionadas") ${ }^{13}$ como ovejas a un buen pastor, también les ha dado un arpa ( $\left.\psi \alpha \lambda \tau \tau^{\prime} \rho เ o v\right)$ y una cítara. Frente al desborde pasional de la acedia, el sonido del arpa,

12 Así pueden ser entendidos, en efecto, los ocho $\lambda o \gamma \iota \sigma \mu o$. Ver al respecto Guillaumont, 1971: 63-84.

13 Cf. Disc. 65. Este tópico lo hemos trabajado en otro lugar: Vázquez, 2019c: 76-78. 
del salterio, dirá nuestro autor, posibilitará que las ovejas vuelvan a pacer al pie del monte Sinaí, es decir, se alimenten de la ley del Señor (De mal. cogit. 17).

Son diversos los textos en los que Evagrio propone la palabra de la salmodia como aquella que puede curar o calmar las pasiones en general y la irascibilidad en particular. Recordemos que en la acedia hay una eclosión de la parte irascible del alma. En este sentido, el remedio de la salmodia es también claramente aplicable a ella:

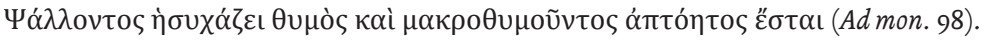

El que salmodia apacigua su ira, y el paciente vivirá sin temor (Ad mon. 98; trad. Rubio Sadia, 1995).

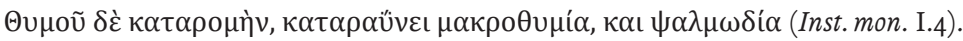

Salmodia y paciencia pacifican la embestida de la irascibilidad (Inst.mon. I.4).

Contra el pensamiento que no reconoce como la modulación de los salmos cambia el equilibrio corpóreo (Antirrh. VI.22).

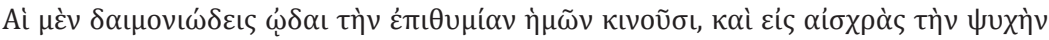

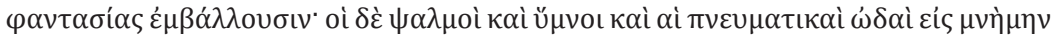

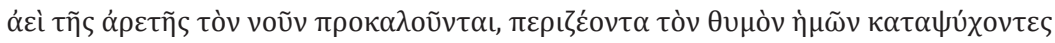

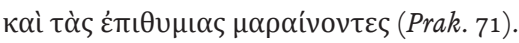

Los cantos demoníacos excitan nuestra concupiscencia y arrojan al alma hacia imaginaciones vergonzosas; pero los salmos, los himnos y los cánticos espirituales invitan al intelecto al recuerdo constante de la virtud, enfriando nuestra ardiente irascibilidad y extinguiendo nuestros deseos (Prak. 71).

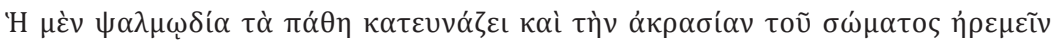

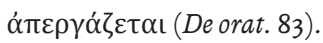

La salmodia calma las pasiones y apacigua la falta de dominio del cuerpo (De orat. 83; trad. Rubio Sadia, 1995).

Dysinger, el estudioso de Evagrio que más se ha ocupado del tema de la salmodia,

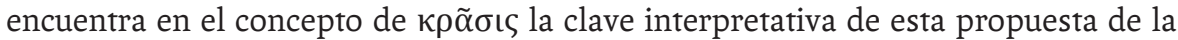

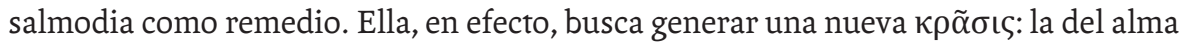
con las virtudes.

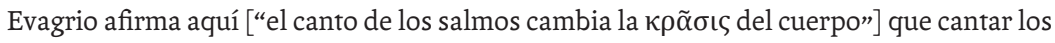
salmos cambia la $\kappa \rho \tilde{\alpha} \sigma \iota \varsigma$, que es el complejo y delicado balance de humores considerado responsable de la salud y la enfermedad. [En los capítulos 69 a 71 del Tratado Práctico] Evagrio sugiere que una salmodia "sin distracciones" contribuye al establecimiento de

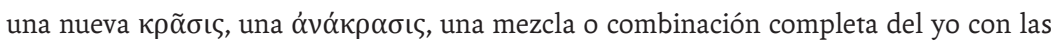
virtudes (Dysinger, 2005: 128).

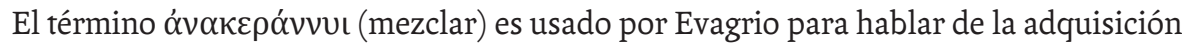
de las virtudes (Prak. 70). La palabra que impulsa al ejercicio de la virtud es la que de alguna manera mezcla al alma con la virtud, permitiendo que la primera participe incipientemente de la segunda. En el capítulo 69 del Tratado Práctico, el Póntico usa el verbo $\pi \rho о \kappa \alpha \lambda \varepsilon ́ \omega$ para designar la acción que, con respecto a la virtud, ejercen los salmos: éstos "invitan al intelecto al recuerdo constante de la virtud". La palabra llama, invita $(\pi \rho \circ \kappa \alpha \lambda \varepsilon \dot{\varepsilon} \omega)$ al recuerdo constante de la virtud y a su ejercicio. Permite una 


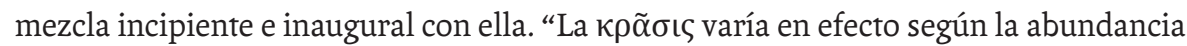
o la falta de los elementos de tal o cual virtud" (Disc. 113).

Aquella clave que nos proporciona Dysinger da mayor inteligibilidad al recurso terapéutico contra la acedia que Evagrio propone en el Tratado Práctico y que más arriba citáramos: el de dividir el alma y darle a aquella las palabras de consuelo del salmo. El alma, al ponerse fuera de sí, distanciándose de sí y mirándose de fuera, se identifica con esa mirada y se apropia de ella: esa mirada se hace la suya propia. Y se trata de una mirada que se realiza desde un yo mezclado con la virtud, desde un yo que ha comprendido que no tiene motivos para la tristeza teniendo un Dios como el que tiene, que es su salud.

\section{Conclusiones}

La concepción de la acedia evagriana que hemos intentado reconstruir siguiendo algunas claves hermenéuticas presentes en los desarrollos de los estudiosos Bernard Forthomme y Gabriel Bunge, nos ha permitido a su vez abordar el tema de la palabra como instancia curativa en la obra de Evagrio Póntico. Si la acedia es un $\lambda$ oүı $\sigma \mu$ ó $q$ que actúa por debajo de la conciencia introduciendo palabras, dando al complejo pasional que la caracteriza un sentido lógico en cuya base existe una imagen desvirtuada de sí, la palabra que permite superarla es aquella que, atendiendo a esta naturaleza, desenmascara - por su poder develador- el pensamiento que está operando detrás de los movimientos pasionales intensos de la acedia y devuelve -por su virtualidad especular- una imagen de sí reconstruida y verdadera, en suma, un -como dirá Forthomme- "alegre saber sobre sí" (Forthomme, 2000: 503) que sacude la negligencia, restaura la esperanza e impide así que el monje "abandone el estadio", vale decir, que abandone la vida de acuerdo a su naturaleza de voũ 


\section{Bibliografía}

\section{Fuentes}

\section{Ediciones}

»Évagre le Pontique (1971). Traité pratique ou le moine. Tome II. Ed. bilingüe. Trads. Guillaumont, A. y Guillaumont, C. París: Cerf. (SC 171).

»Évagre le Pontique (1985). Les six Centuries des 'Kephalaia gnostica'. Ed. Guillaumont, A. Turnhout: Brepols. (PO 134 [28.1]).

»Évagre le Pontique (1987). Scholies aux Proverbes. Ed. bilingüe. Trad. Géhin, P. París: Cerf. (SC 340).

"Évagre le Pontique (1989/2008). Le gnostique ou a calui qui est devenu digne de la science. Ed. bilingüe. Trads. Guillaumont, A. y Guillaumont, C. París: Cerf. (SC 356).

»Évagre le Pontique (1998). Sur les pensées. Ed. bilingüe. Trad. Géhin, P., Guillaumont, A. y Guillaumont, C. París: Cerf. (SC 438).

"Évagre le Pontique (2007). Chapitres des disciples d'Évagre. Ed. bilingüe. Trad. Géhin, P. París: Cerf. (SC 514).

» Evagrio Pontico (1996). Gli otto spiriti della malvagità. Ed. bilingüe. Trad. Moscatelli, F. Milán: San Paolo Edizioni.

"Evagrio Pontico (2006). A Eulogio. Sulla confessione dei pensieri e consigli di vita. Ed. bilingüe. Trad. Coco, L. Milán: San Paolo Edizioni.

» Evagrius of Pontus (1990). Exhortations to Monks. URL: http://www.ldysinger. com/Evagrius/06_Sents/00a_start.htm. Consultado el 22 de enero del 2020.

» Evagrius of Pontus (1990). Scholia on Psalms. Ed. bilingüe. Trad. Dysinger, L. En: "St. Evagrius Ponticus (345-399). The Genre of Sentences", Monastic Spirituality Self-Study. URL: http://www.ldysinger.com/Evagrius/08_Psalms/00a_start.htm. Consultado el 22 de enero del 2020.

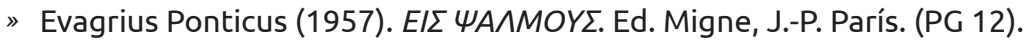

"Evagrius Ponticus. Anthirretikos. Texto griego perdido. Texto de la copia siríaca con retroversión griega: "Evagrius Ponticus" (1912). Fankenberg W. (ed.). Abhandlungen, Göttinger Akademie der Wissenschaften 13.2, 472-545.

» Jean Cassien (1955). Conférences (I-VII), tome I. Ed. bilingüe. Trad. Pichery, E. París: Cerf. (SC 42 bis).

\section{Traducciones}

"Evagrio Póntico (1995). A los monjes. Trad. Rubio Sadia, J. P. En: González Villanueva, J. I. (ed.). Obras Espirituales Madrid: Ciudad Nueva, 177-211.

» Evagrio Póntico (1995). Sobre la Oración. Trad. Rubio Sadia, J. P. En: González Villanueva, J. I. (ed.). Obras Espirituales. Madrid: Ciudad Nueva, 229-275.

" Evagrio Pontico (2005). Contro i pensieri malvagi. Antirrhetikos. Trad. Lazzeri, V. Magnano: Qiqajon. 
"Evagrio Pontico (2008). Trattato Pratico. Trad. Bunge, G. Magnano: Qiqajon.

»Evagrius of Pontus (2003). Exhortations to Monks. Trad. Sinkewicz, R. En: Idem. Evagrius of Pontus, the Greek Ascetic Corpus. Oxford: Oxford University Press, 218223.

\section{Bibliografía complementaria}

» Bunge, G. (2007). Akèdia. La doctrine spirituelle d'Èvagre le Pontique sur l'acedie. Bellefontaine: Abbaye de Bellefontaine.

»Daly, R. (2007). "Before depression: the medieval vice of acedia", Psychiatry 70.1, 30-51.

» Despland, J.-N. (2013). “La tristesse en présence de Dieu: de l'acédie à la mélancolie", Psychothérapies 33, 71-80.

"Dysinger, L. (2005). Psalmody and Prayer in the Writings of Evagrius Ponticus. Oxford: Oxford University Press.

» Forthomme, B. (2000). De l'acédie monastique à l'anxio-dépression. Histoire philosophique de la transformation d'un vice en pathologie. París: Synthélabo.

» Forthomme, B. (2003). “L'acédie, la dépression, la mélancolie et l'ennui". En: Charbonneau, G. y Legrand, J. M. (eds.). Dépressions et paradépressions. París: Le Cercle Herméneutique, 21-26.

»Forthomme, B. (2005). "Émergence et résurgence de l'acédie". En: Nabert, N. (ed.). Tristesse, acédie et médecine des âmes dans la tradition monastique et cartusienne: anthologie de textes rares et inédits, XIIIe-XXe siècle. París: Beauchesnes, 15-35.

»Géhin, P. (2016). “L'Ecclésiaste à l'épreuve de l'allégorie dans les scholies d'Évagre le Pontique". En: Mellerin, L. (ed.). La réception du livre de Qohélet (ier-xiiie s.). París: Cerf, 133-148.

» Guillaumont, A. (1971). “Introduction”. En: Idem. Evagrio Póntico, Traité Pratique. Tome I. París: Cerf, 15-124.

" Joest, Ch. (2018). "Die arithmetische Feinstruktur im Traktat De oratione des Evagrios Pontikos", Vigiliae Christianae 72, 21-40.

" Kalvesmaski, J. (2016). "Evagrius in the Byzantine Genre of Chapters". En: Kalvesmaki, J. y Young, R. (eds.). Evagrius and His Legacy. South Bend: University of Notre Dame Press, 257-287.

" Konstantinovsky, J. (2016). "Evagrius Ponticus and Maximus the Confessor: The building of the Self in Praxis and Contemplation". En: Kalvesmaki, J. y Young, R. (eds.). Evagrius and His Legacy. South Bend: University of Notre Dame Press, 128153.

» Lain Entralgo, P. (2005). La curación por la palabra en la Antigüedad Clásica. Barcelona: Anthropos.

» Mallol, A. (2011). Juan Casiano y la discreción. Córdoba: Ediciones del Copista.

" Marsili, S. (1936). Giovanni Cassiano ed Evagrio Pontico. Roma: Editrice Anselmiana.

»Nault, J.-Ch. (2006). La saveur de Dieu. L'acédie dans le dynamisme de l'agir. París: Cerf. 
»Peretó Rivas, R. (2017). "Angustia y acedia como patología en el monacato medieval. Manifestaciones y recursos curativos", Anuario de Estudios Medievales 47.2, 769-794.

» Peretó Rivas, R. (2018). Evagrio Póntico y la acedia. Nueva York: Peter Lang.

» Peretó Rivas, R. (2019a). “Evagrius Ponticus' Kephalaia gnostica two versions. New Discussion on their Authenticity", Adamantius 24, 485-492.

» Peretó Rivas, R. (2019b). “El 'demonio errante' en Evagrio Póntico y José Hazzaya”, Salmanticensis 66, 311-329.

» Ramelli, I. (2017). “Origen to Evagrius". En: Tarrant, H., Layne, D. A., Baltzly, D. y Renaud, F. (eds.). "Brill's Companion to the Reception of Plato in Antiquity". Boston: Brill, 271-291 (Brill's Companions to Classical Reception 13).

»Vázquez, S. H. (2017a). “El Abba como Gnóstico en Evagrio Póntico. El rol pedagógico-medicinal de su palabra y sus fuentes", Studia Monastica 59, 251-268.

»Vázquez, S. H. (2017b). "La palabra y su dimensión terapéutica frente a la enfermedad del alma en Evagrio Pontico", Rivista di Storia e Letteratura Religiosa 53, 3-31.

»Vázquez, S. H. (2018). "La enfermedad del alma en el filósofo tardoantiguo Evagrio Póntico: entre ignorancia y filautía", Anales del Seminario de Historia de la Filosofía 35, 323-343.

» Vázquez, S. H. (2019a). “Aportes para una historia de la metáfora del espejo. El horizonte logo-terapéutico de su tematización en Evagrio Póntico y otros autores tardoantiguos", Revista de Historia de la Psicología 40, 45-54.

» Vázquez, S. H. (2019b). "La distinción entre pecado y psicopatología en la concepción de acedia de Tomás de Aquino. Posibles relaciones con desarrollos de la psicología contemporánea", Revista Latinoamericana de Psicopatología Fundamental 22.2, 333-359.

» Vázquez, S. H. (2019c). “La noción de logismoí en Evagrio Póntico: el correlato cognitivo de las pasiones enfermas", Éndoxa: Series Filosóficas 43, 67-90.

»Wenzel, S. (1966). “Acedia 700-1200”, Traditio 22, 73-102.

» Young, R. D. (2016). "The Role of Letters in the Works of Evagrius". En: Kalvesmaki, J. y Young, R. (eds.). Evagrius and his Legacy. South Bend: University of Notre Dame Press, 154-174. 
